\title{
Cholinergic Manipulations in the Medial Septal Area: Age-Related Effects on Working Memory and Hippocampal Electrophysiology
}

\author{
Alicja L. Markowska, ${ }^{1}$ David S. Olton, ${ }^{1}$ and Bennet Givens ${ }^{2}$ \\ 'Department of Psychology, The Johns Hopkins University, Baltimore, Maryland 21218-2686 and 'Department of \\ Psychology, The Ohio State University, Columbus, Ohio 43210
}

Aged rats have impairments in several types of cognitive functions, including spatial working memory (WM), that are dependent upon the septohippocampal cholinergic system. The present series of experiments was designed to assess the effectiveness of pharmacological manipulations of the medial septal area (MSA) in order to influence the physiology of the septohippocampal pathway and, therefore, the brain functions in which this pathway participates. Aged (22MO) and young (4MO) Fischer-344 rats received microinfusions into the MSA with either saline, the muscarinic agonist, oxotremorine (OXO), or the muscarinic antagonist, scopolamine (SCOP). Working memory was tested in a T-maze spatial alternation task, prior to infusion, immediately after infusion, and $\mathbf{9 0} \mathrm{min}$ after infusion. Hippocampal theta activity and the population excitatory postsynaptic potential (pEPSP) of the dentate gyrus to perforant path stimulation were recorded immediately following behavioral testing at each of the three time periods.

In $22 \mathrm{MO}$ rats, intraseptal OXO $(0.5 \mu \mathrm{g}, 2 \mu \mathrm{g}, 5 \mu \mathrm{g})$ produced a dose-dependent improvement in choice accuracy, a shift of the hippocampal theta peak to a lower frequency and $a$ higher peak power, and an increase in the initial slope of pEPSP. OXO, $0.1 \mu \mathrm{g}$, did not have an effect on behavior or hippocampal physiology and OXO, $10 \mu \mathrm{g}$, produced an impairment in performance. In $4 M O$ rats, OXO did not affect choice accuracy, nor the PEPSP slope, but altered hippocampal theta peak frequency and power similarly as in 22MO. The lowest behavlorally effectlve dose, $0.5 \mu \mathrm{g} \mathrm{OXO}$, did not influence WM performance when infused into the lateral ventricles (intracerebroventricularly) of either $22 \mathrm{MO}$ or $4 \mathrm{MO}$ rats.

SCOP $(2 \mu \mathrm{g}, 5 \mu \mathrm{g}, 15 \mu \mathrm{g})$ decreased choice accuracy in a dose-dependent fashion in both $22 \mathrm{MO}$ and $4 \mathrm{MO}$ rats. However, in 22MO rats, the behavioral dose-response curve for scopolamine was shifted towards greater sensitivity. SCOP produced a shift of the hippocampal theta to a higher frequency and a lower peak power, and a decrease in the initial slope of pEPSP. In $4 M O$ rats, SCOP altered

Received Mar. 1, 1994; revised Aug. 11, 1994; accepted Sept. 14, 1994.

This research was supported by NIA Grant AGI00015 to D.O. and A.M. We thank J. Chrobak and K. Frick for helpful comments, M. Barra and E. Spencer for assistance in behavioral testing and analyzing the data, and $\mathrm{M}$ Barra and M. Markowska for help in preparing the manuscript.

Correspondence should be addressed to Alicja L. Markowska, Ph.D., Neuromnemonics Laboratory, Department of Psychology, The Johns Hopkins University, Baltimore, MD 21218-2686.

Copyright (C) 1995 Society for Neuroscience 0270-6474/95/152063-11\$05.00/0 hippocampal theta similarly to $22 \mathrm{MO}$, but did not affect the pEPSP slope.

These results indicate that (1) cholinergic receptors in the MSA are a useful target for drugs to improve WM in aging rats, (2) age-related changes in the activity of the septohippocampal pathway may increase its sensitivity to drugs which alter its activity, and (3) alterations in hippocampal physiology may contribute differently to changes in WM in young and in old rats.

[Key words: cholinergic system, oxotremorine, scopolamine, medial septal area, recent memory, spatial memory, theta, evoked potential, aging]

Aged rats are impaired in several types of cognitive functions including spatial working memory (Ingram et al., 1981; deToledo-Morell et al., 1988; Aggleton et al., 1989). The brain mechanisms underlying this type of memory involve the septohippocampal cholinergic system (Olton et al., 1990, 1992). Cholinergic neurons in this system undergo age-associated alteration (Biegon et al., 1986; Fischer et al., 1987, 1989, 1991ab; Altavista et al., 1988, 1990) and their dysfunction has been linked to cognitive impairments (Bartus et al., 1985; Perry, 1986; Olton and Wenk, 1987).

The neural changes in the septohippocampal system are strongly correlated with the extent of age-related memory impairments (Ingram et al., 1981; Biegon et al., 1986; Fischer et al., 1988). These changes include cell loss in the basal forebrain cholinergic system (Biegon et al., 1986; Fischer et al., 1987, 1988; Altavista et al., 1988, 1990; Gomez-Pinilla et al., 1989), as well as a decline in parameters of $\mathrm{ACh}$ synthesis or release (Gilad et al., 1987), a decrease in the number of perforated synapses per neuron in the granule cells of the dentate gyrus (Geinisman et al., 1986), a decrease in the duration of long-term enhancement in the hippocampus (Barnes and McNaughton, 1985), an alteration in the threshold for kindling (deToledo-Morrell et al., 1988), an alteration in hippocampal electrophysiology (Lamour et al., 1984, 1989; Landfield et al., 1988; Lebrun et al., 1990), and a change in brain glucose metabolism (Gage et al., 1984). Consequently, interventions that attempt to ameliorate these age-related changes may improve performance in aged rats (Fischer et al., 1987, 1989; Markowska et al., 1994).

Attempts to improve mnemonic processes with treatments that enhance cholinergic function by oral or systemic administration of drugs have led to inconsistent results (Bartus and Dean, 1985; Bartus et al., 1985). Direct intracranial microinfusion allows for selective targeting of the cholinergic receptors that mediate the mnemonic processes, and therefore may help resolve these inconsistencies. In the present study, the cholinergic receptors are 
targeted in the medial septal area (MSA), which contains the nuclei that provide a cholinergic innervation to the hippocampus, both to principal cells and to interneurons (Frotscher and Leranth, 1985; Leranth and Frotscher, 1989), and also provide a large GABAergic innervation predominantly to GABAergic interneurons (Freund and Antal, 1988).

The neurons in MSA modulate mnemonic processes. Lesions of the MSA (Hagan et al., 1988; Numan and Quaranta, 1990; Decker et al., 1992) or administration of cholinergic antagonists (Beatty and Bierly, 1985; Hagan et al., 1986; Decker and Gallagher, 1987) impair memory. Septohippocampal neurons are cholinoceptive in both young and old rats (Lamour et al., 1989): muscarinic agonists and muscarinic antagonists produce increased and decreased neural activity, respectively. Infusions of drugs into the MSA have provided evidence that alteration of the medial septal transmission can influence working memory in young rats, suggesting an important role of the septal cholinergic receptors in processing information for spatial working memory (Chrobak et al., 1989; Brioni et al., 1990; Givens and Olton, 1990; Mizumori et al., 1990).

The present study was designed to determine if manipulations of the cholinergic receptors on the MSA neurons can influence the spatial working memory and modulate hippocampal physiology in old (22MO) and in young rats (4MO). Two specific hypotheses were tested: (1) that stimulation of the MSA cholinergic receptors by the cholinergic agonist, oxotremorine, will improve memory, and (2) that the blockade of the MSA cholinergic receptors by the cholinergic antagonist, scopolamine, will impair memory. The inclusion of young rats addresses the important question of whether the effect of cholinergic drugs on spatial working memory and hippocampal physiology differs as a function of age.

In order to control for any possible nonspecific effects of the intraseptal infusion, saline was given as a vehicle control. The level of choice accuracy across all rats was equated by adjusting the intertrial interval for each rat. This technique permitted a direct comparison of the effectiveness of the interventions for all rats at all ages without the confounding factor of different baselines of choice accuracy (Bartus et al., 1985).

\section{Materials and Methods}

\section{Animals}

The subjects were male, Fisher-344 rats, from the NIA colony at Harlan. At the start of the experiment, they were 21-22 months old (22MO; $n$ $=16)$, and 4 months old ( $4 \mathrm{MO} ; n=12)$. They were housed in hanging wire cages in a colony room with a 12:12 light/dark cycle. Food was available ad libitum. Water was given for about 10 minutes each day at the end of behavioral testing. This schedule maintains body weight at $85 \%$ of the ad libitum level, adjusted for growth. All behavioral testing occurred during the light portion of the light/dark cycle.

\section{Surgery}

Cannula implantation. Each rat was anesthetized with pentobarbital sodium $(50 \mathrm{mg} / \mathrm{kg})$. The scalp was retracted and holes were drilled in the skull for the implantation of guide cannulae, electrodes and jewelers screws. A guide cannula, $10 \mathrm{~mm}$ long, made of stainless steel hypodermic tubing, 26 gauge, was placed above the MSA, with the following coordinates from bregma: $\mathrm{AP}=+0.7 \mathrm{~mm}, \mathrm{~L}= \pm 1.5 \mathrm{~mm}$, and $\mathrm{V}=$ $4.6 \mathrm{~mm}$ below the dura at a $15^{\circ}$ angle toward midline. One guide cannula was placed just above each lateral ventricle, at coordinates $\mathrm{AP}=$ $-0.8 \mathrm{~mm}, \mathrm{~L}= \pm 1.5 \mathrm{~mm}$, and $\mathrm{V}=2.4 \mathrm{~mm}$. The stylet used to occlude the cannulas was a 32 gauge wire, $11 \mathrm{~mm}$ long, with the last $1 \mathrm{~mm}$ bent at a $110^{\circ}$ angle.

\section{Electrode implantation}

A unilateral recording electrode (Teflon-coated $125 \mu \mathrm{m}$ stainless steel wire) was placed with the tip in the dentate hilus, to record both evoked potentials and $E E G$ activity, with coordinates $\mathrm{AP}=-4.0 \mathrm{~mm}, \mathrm{~L}=2.5$ mm lateral, and $\mathrm{V}=-2.0 \mathrm{~mm}$ below the dura. A stimulating electrode (Teflon-coated $120 \mu \mathrm{m}$ stainless steel wire) was lowered into the perforant path with coordinates $\mathrm{AP}=-8.1 \mathrm{~mm}, \mathrm{~L}=4.0 \mathrm{~mm}$, and $\mathrm{V}=$ $2.0 \mathrm{~mm}$ at a $10^{\circ}$ angle away from midline. The stimulating electrode was connected to a Grass Stimulator (model S88), and the recording electrode to an amplifier, filter, oscilloscope, and an A/D acquisition board. Both electrodes were lowered further while stimulating $(0.1 \mathrm{sec}$ $200 \mu \mathrm{A}, 0.1 \mathrm{~Hz}$ ) until a well defined, large amplitude evoked potential with a population spike was recorded. A ground and a reference electrode (single Teflon-coated $250 \mu \mathrm{m}$ stainless steel wires) were placed into the contralateral cortex. The electrodes weie altached to a gold pir that was inserted into a plastic connector strip mounted on the skull. The cannulae, electrodes and connector were fixed into place with dental acrylic anchored to the skull with small screws.

\section{Spatial alternation}

Apparatus. The T-maze had a stem, $35 \mathrm{~cm}$ long, and two arms, each $30 \mathrm{~cm}$ long. A cup, $2 \mathrm{~cm}$ diameter and $1 \mathrm{~cm}$ deep, was located $2 \mathrm{~cm}$ from the distal end of each arm. The sides of the stem and arms extended $4 \mathrm{~mm}$ above the surface of the maze floor. A guillotine door was located $10 \mathrm{~cm}$ from the distal end of the stem, and separated the stem from the start platform. The maze was placed on the table, $70 \mathrm{~cm}$ above the floor of the room.

Shaping. Shaping took place for 3-4 d to train each rat to run to the end of the arm and drink water. During the first day, water was placed in many cups spread throughout the maze. Each rat was placed on the maze for $10 \mathrm{~min}$ to explore the maze and drink the water. During each successive day, the number of water cups was reduced and they were placed closer to the ends of each arm. At the end of shaping, water was present only in the cup at the end of each arm.

Training. For each trial, a few drops of water were placed in the cup at the end of one arm. For the first forced trial, the arm containing water was chosen randomly with the constraint that the same arm was not chosen for more than two consecutive sessions. A block of wood was placed at the entrance to the other arm. The rat was placed on the starting platform, the guillotine door was raised, and the rat was allowed to go to the available arm and drink the water.

For each subsequent choice trial, water was placed in the arm opposite to the arm chosen on the previous trial. The rat was placed on the starting platform, the guillotine door was raised, and the rat was allowed to choose one arm. If the arm had water, the rat was allowed to drink it, and a correct response was recorded. If the arm did not have water, the rat was removed immediately, and an incorrect response was recorded. Consequently, the optimal strategy for the rat on each choice trial was to remember the arm entered during the previous trial and choose the opposite arm. Each session had one forced trial and 20 choice trials. Choice accuracy for choice trials was the percentage of correct responses in the 20 choice trials of each session. Training occurred $7 \mathrm{~d} /$ week with 1 session/day.

Prior to surgery, the delay interval (DI) between choices was $30 \mathrm{sec}$. During the delay interval the rat was placed in a waiting cage. Postoperatively, the DI was either $30 \mathrm{sec}, 1 \mathrm{~min}$, or $2 \mathrm{~min}$. For each rat. the DI was adjusted to provide a consistent level of choice accuracy under $80 \%$. If choice accuracy in the no-drug conditions was greater than $80 \%$ for three consecutive sessions, the DI was increased to the next longer DI. The adjusted level of choice accuracy was high enough to ensure that the rats were rewarded frequently enough to support behavior, and low enough so that a substantial range of improvement was available.

\section{Drug microinfusion}

Drugs were delivered through an injector made of 32 gauge stainless steel tubing, approximately $30 \mathrm{~mm}$ long, bent $12 \mathrm{~mm}$ from the end, and connected to polyethylene tubing (PE-10) that was attached to a $10 \mu \mathrm{l}$ syringe (Hamilton) mounted on a microinfusion pump (Orion), calibrated to deliver fluid at a rate of $0.1 \mu \mathrm{l} / \mathrm{min}$. For infusion, the stylet was removed, the injector was inserted into the guide cannula, and 0.5 $\mu l$ of a drug solution was delivered during $5 \mathrm{~min}$. The injector was left in place for an additional minute before removal. The stylet was reinserted into the guide cannula. A minimum of $2 \mathrm{~d}$ with no drug infusion was given between microinfusions. 


\section{Drug doses}

Oxotremorine (OXO; $0.1 \mu \mathrm{g}, 0.5 \mu \mathrm{g}, 2 \mu \mathrm{g}, 5 \mu \mathrm{g}, 10 \mu \mathrm{g}$ ), scopolamine hydrochloride (SCOP; $2 \mu \mathrm{g}, 5 \mu \mathrm{g}, 15 \mu \mathrm{g}$ ), and saline (SAL) were used. OXO and SCOP were dissolved in saline and stored frozen $\left(-40^{\circ} \mathrm{C}\right)$ at their final concentrations in $100 \mu$ l aliquot.

\section{Electrophysiological recording}

All electrophysiological measurements were taken in a recording chamber $(15 \mathrm{~cm} \times 15 \mathrm{~cm} \times 18 \mathrm{~cm})$. Each rat was attached to a cable containing dual FET operational amplifiers that sent signals through a commutator to a bandpass filter $(1-100 \mathrm{~Hz})$, amplifiers $(1000 \times)$, and an analog-to-digital $(512 \mathrm{~Hz})$ interface board that digitized the signal. The digital pulses were sent to software developed by BrainWave Systems, Inc. (Denver, $\mathrm{CO}$ ) with which all analyses were performed.

The EEG signals were transformed by fast Fourier transformation (FFT) to spectral power at $0.5 \mathrm{~Hz}$ increments from $1-20 \mathrm{~Hz}$. From the transformed data, the peak frequency and peak power (power in $0.5 \mathrm{~Hz}$ band surrounding peak frequency) were determined. The power at each frequency was averaged over the 10 min recording period.

For the pEPSP of the dentate gyrus to perforant path stimulation, a complete current-response curve was elicited from each rat over a range of currents $(100-600 \mu \mathrm{A})$. From this curve, a maximum response was determined, and the current needed to elicit $50 \%$ of the maximum response, to the closest $100 \mu \mathrm{A}$, was determined for each rat. The evoked response to 20 single pulses $(0.1 \mathrm{~Hz})$ was taken (interspersed with recordings of EEG). Off-line analysis determined the initial slope of the pEPSP, the amplitude of the population spike, and the pEPSP amplitude. All data acquisition and analysis was carried out on an electrophysiological workstation (BrainWave, Inc. Denver, CO).

\section{General procedure}

Prior to surgery, each rat was trained in a spatial alternation procedure for a total of 200 trials. After surgery, each rat was given 1 week to recover before testing was initiated.

On the test days, behavioral testing was followed by recording in the recording chamber at three difterent times; preinfusion was taken before microinfusion of the drug (baseline); postinfusion just after microinfusion of the drug followed by behavioral testing (Post 1), and postinfusion $90 \mathrm{~min}$ after the microinfusion (Post 2). Behavioral testing was started $1 \mathrm{~min}$ or $90 \mathrm{~min}$ after infusion, restricted to $15 \mathrm{~min}$ or 20 choice trials whichever came first, and was immediately followed by electrophysiological recording that lasted $10 \mathrm{~min}$.

On the days when rats were not given an infusion, one behavioral test session was given. The rats were tested $5 \mathrm{~d}$ a week throughout the entire testing phase. The experimenter did not know the specific drug being injected. Each rat was given no more than 10 infusions with at least $2 \mathrm{~d}$ between infusions. The order of treatment was randomized. Some drug-dose combinations were tested more than once in the same rat to ensure an accurate assessment of performance.

\section{Histology}

Following the completion of all testing, Chicago sky blue dye $(0.5 \%$; $0.5 \mu \mathrm{l}$ ) was injected into the MSA. Six minutes after the dye infusion, the rat was anesthetized and prepared for cardiac perfusion with saline and then $10 \%$ formalin. Sections $(50 \mu \mathrm{m})$ were taken through the septal and hippocampal regions to determine the site of the infusion and the tip of the recording and the stimulating electrode, respectively.

\section{Data analysis}

For spatial alternation, the data is expressed as mean choice accuracy for each block of 20 trials (the percentage of correct responses in 20 choice trials) \pm the standard error of the mean (SEM).

In the analyses of hippocampal theta rhythm, two measures were calculated and compared: the peak frequency and the peak power. For evoked potentials, three measures were recorded: the initial slope of the pEPSP, the population spike, and the pEPSP amplitude. The population spike and pEPSP amplitude were not systematically affected by any of the behavioral or drug conditions, and are not further reported.

The behavioral and electrophysiological measurements were analyzed by a mixed model analysis of variance (ANOVA) with the age and drug/dose condition as the two independent variables, and choice accuracy, peak frequency, peak power, and the initial slope of the pEPSP as dependent measures. For repeated measures the experimental values from baseline, Post 1 , and Post 2 were analyzed.

Omnibus mixed-model ANOVAs were conducted for OXO and SCOP: 2 (4MO vs $22 \mathrm{MO}) \times 6$ (doses for OXO or 4 for SCOP) $\times 3$ (baseline vs Post 1 vs Post 2). Two focused ANOVAs (dose $\times$ period) were also conducted to analyze the dose effects for $4 \mathrm{MO}$ and $22 \mathrm{MO}$ rats separately and the contrast tests were applied where appropriate to isolate significant differences. This analysis was justified by the presence of several interactions between age, dose, and period.

Dose effect was indicated by a difference in the dependent variables between drug infusion and saline infusion during Post 1 and Post 2 . In order to control for differences in baseline between doses, additional one-way ANOVAs comparing dependent variables between baseline, Post 1 , and Post 2 were performed for each dose, separately.

In order to control possible interactions between various delay intervals and drug induced changes, the lengths of the delay intervals were correlated with the amount of change in the choice accuracy. For correlations, Pearson correlation for pairwise comparisons with Bonferroniadjusted probabilities was used.

Four rats did not complete all drug testing, producing different degrees of freedom in the analysis of some tasks. Because the highest dose of OXO, $10 \mu \mathrm{g}$, produced side effects (tremors and hyperactivity) which interfered with electrophysiological recording, the electrophysiological data were not collected at this dose.

\section{Results}

\section{Histology}

The tips of the injectors were situated in the medial septal nucleus or just above the lateral ventricles. Histological analysis of the spread of the sky blue dye indicated that the infusions were restricted to the MSA, localized to a spherical area with a diameter of about $1 \mathrm{~mm}$ including the medial septal nucleus, the vertical limb of the diagonal band, and a portion of the horizontal limb of the diagonal band. In two cases, dye infusion was also observed in a portion of the lateral septum.

The tips of the recording and stimulating electrodes were localized in the hilar region of the dentate gyrus, and the perforant path, respectively. There were some gliosis and tissue damage around electrodes in a few cases. One rat had infections in the cortex surrounding the guide cannula, and was excluded from the data analyses.

\section{Spatial alternation}

Training. 4MO rats learned the task quickly and during the last three sessions (sessions 8-10) had a mean choice accuracy of $79 \pm 3 \%$ (Fig. 1)

In $22 \mathrm{MO}$ rats, choice accuracy improved during testing, but the rate of this improvement was not as great as in $4 \mathrm{MO}$ rats [age $\times$ sessions, $F(9,234)=2.0, p<0.05$ ]. During sessions 8 10 , the mean choice accuracy of the $22 \mathrm{MO}$ group was $64 \pm$ $4 \%$.

Baseline accuracy. A total of 250 infusions were given to 28 rats. The mean delay interval for the old rats was $34.5 \pm 1.5$ $\mathrm{sec}$ and for the young rats $60.0 \pm 4.0 \mathrm{sec}$. Some of the delay intervals of aged animals overlapped with those of the young rats. In the old group, $85 \%$ of the tests following infusions were done with a $30 \mathrm{sec}$ delay, and $15 \%$ with a $60 \mathrm{sec}$ delay interval. In the young group, $38 \%$ of tests were done with a $30 \mathrm{sec}$ delay, $43 \%$ with a $60 \mathrm{sec}$ delay and $19 \%$ with a $120 \mathrm{sec}$ delay interval.

Saline vehicle. Saline, when compared to baseline, had no effect on choice accuracy in $4 \mathrm{MO}$ or in $22 \mathrm{MO}$ rats, indicating that the infusion process itself did not alter behavior (Fig. 3).

Oxotremorine. There was a significant overall effect of $\mathrm{OXO}$ [dose effect including SAL intraseptal and SAL ICV; $F(6,138)$ $=4.4, p<0.001]$ that was dependent upon the age, dose, and period [age $\times$ dose, $F(6,138)=3.2, p<0.01$; age $\times$ period, 


$$
\begin{gathered}
\text { T-MAZE AI TFRNATION } \\
\text { INITIAL TRAINING }
\end{gathered}
$$

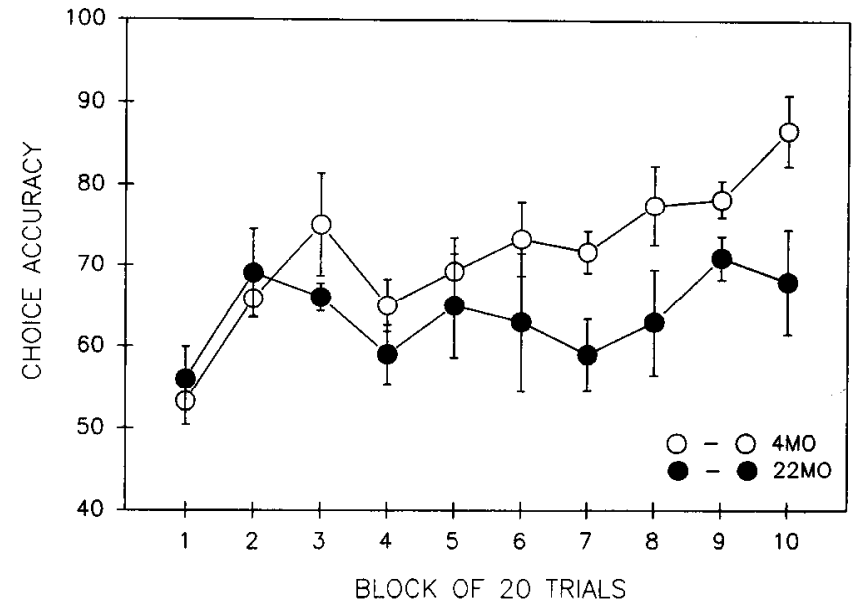

Figure 1. Acquisition of spatial alternation in the $4 \mathrm{MO}$ and the $22 \mathrm{MO}$ rats. The mean choice accuracy of the $4 \mathrm{MO}$ group (open circles) and the 22MO (solid circles) are presented during 11 preoperative blocks of 20 trials. The preoperative acquisition to the task was slower in the $22 \mathrm{MO}$ rats as compared to the $4 \mathrm{MO}$ rats. Vertical lines indicate the SEM.

$F(2,276)=6.4, p<0.01$; dose $\times$ period, $F(12,276)=3.7, p$ $<0.001$; age $\times$ dose $\times$ period, $F(12,276)=3.0, p=0.001]$.

In the $4 \mathrm{MO}$ group, choice accuracy showed no significant effect following OXO infusions (Fig. 3, top left). There was no significant correlation (Pearson correlation, $p>0.5$ ) between the delay interval and drug-induced changes in the choice accuracy.

In the $22 \mathrm{MO}$ group, choice accuracy was significantly increased following OXO as compared to SAL [focused ANOVA, dose effect, $F(6,70)=4.2, p<0.001 ;$ dose $\times$ period, $F(12,140)$ $=6.3, p<0.001$; Figs. 2, 3, bottom left $]$. The contrasts further revealed that the magnitude and duration of the improvement in choice accuracy increased as the dose increased to $5 \mu \mathrm{g}$; while OXO, $0.1 \mu \mathrm{g}$, had no hehavioral effect, OXO, $0.5 \mu \mathrm{g}, 2 \mu \mathrm{g}$, and $5 \mu \mathrm{g}$, improved choice accuracy on Post 1 (as compared to saline; $p<0.001,0.005$, and 0.001, respectively). On Post 2, choice accuracy following two lower doses of OXO, $0.5 \mu \mathrm{g}$ and $2 \mu \mathrm{g}$, had returned to saline levels, while choice accuracy following OXO, $5 \mu \mathrm{g}$, was still elevated $(p<0.01)$. The highest dose of $\mathrm{OXO}, 10 \mu \mathrm{g}$, produced a significant impairment of choice accuracy on both Post 1 and Post 2 ( $p$ values $<0.05$ ). This impairment was probably due to nonspecific side effects (tremors and hyperactivity) produced by this dose of OXO. Infusion of $0.5 \mu \mathrm{g}$ OXO intracerebroventricularly did not result in an alteration of behavior.

A pattern of results similar to that described above was revealed by comparing Post 1 and Post 2 against its own baseline for cach dosc: OXO, $0.1 \mu \mathrm{g}$, had no bchavioral effect; $O X O$ in doses $0.5,2,5 \mu \mathrm{g}$ produced a significant increase in choice accuracy at Post $1(p<0.001, p<0.05$, and $p<0.001$, respectively), while $\mathrm{OXO}$ in doses of $10 \mu \mathrm{g}$ produced impairment. This effect approached significance $(p=0.06)$. There was no significant correlation (Pearson correlation, $p>0.5$ ) between the delay interval and drug-induced changes in the choice accuracy.

Scopolamine. The overall effect of SCOP was significant

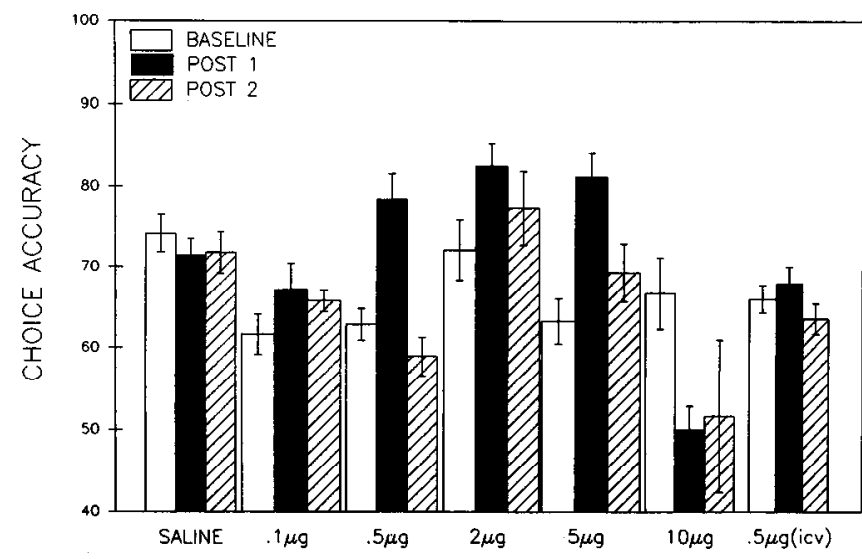

Figure 2. Choice accuracy in spatial alternation following infusions of OXO in the $22 \mathrm{MO}$ rats. Choice accuracy is expressed as the percentage of correct responses in blocks of 20 trials. The data are presented following intraseptal SAL, OXO, $0.1 \mu \mathrm{g}, 0.5 \mu \mathrm{g}, 2 \mu \mathrm{g}, 5 \mu \mathrm{g}$, $10 \mu \mathrm{g}$, and intraventricular (i.c.v.) $\mathrm{OXO}, 0.5 \mu \mathrm{g}$. Performance during baseline is indicated by the open bars, during Post 1 by the solid bars, and during Post 2 by the cross-hatched bars. Intraseptal OXO, $0.5 \mu \mathrm{g}$, $2 \mu \mathrm{g}$, and $5 \mu \mathrm{g}$, produced significant improvement in choice accuracy. SAL, OXO, $0.1 \mu \mathrm{g}$, and i.c.v. OXO had no effect on choice accuracy. Intraseptal $\mathrm{OXO}, 10 \mu \mathrm{g}$, impaired choice accuracy.

[dose effect, $F(3,90)=12.3, p<0.001 ;$ dose $\times$ period, $F(6,180)=13.7, p<0.001$; Fig. 3 , right]. In $4 \mathrm{MO}$ rats, choice accuracy was impaired by SCOP as compared to $S \Lambda \mathrm{L}$ [Focused ANOVA, dose effect, $F(3,44)=5.0, p<0.01$; Fig. 3, top right]. The contrasts further revealed a dose-dependent effect: the magnitude of the impairment in choice accuracy increased as the dose increased. SCOP, $2 \mu \mathrm{g}$, did not alter performance, but the higher doses of SCOP, $5 \mu \mathrm{g}$ and $15 \mu \mathrm{g}$, decreased choice accuracy in Post 1 ( $p$ values $<0.001$ ), and in Post $2(p<0.05$, $p<0.005$, respectively). SCOP, $5 \mu \mathrm{g}$, produced less of a decrease in choice accuracy than SCOP, $15 \mu \mathrm{g}$, in Post $1(p<$ 0.005 ), but a similar decrease in Post 2. A similar pattern of results was obtained when Post 1 and Post 2 were compared against baseline for each dose: the lowest dose of SCOP, $2 \mu \mathrm{g}$, did not alter performance, while the higher doses of SCOP, 5 $\mu \mathrm{g}$, and $15 \mu \mathrm{g}$, decreased choice accuracy in Post 1 ( $p$ values $<0.001$ ), and in Post 2 ( $p<0.05, p<0.01$, respectively).

In the $22 \mathrm{MO}$ rats, choice accuracy was significantly decreased following SCOP as compared to SAL [focused ANOVA, dose effect, $F(3,46)=7.5, p<0.001$; dose $\times$ period, $F(6,92)=8.1$, $p<0.001$; Fig. 3, bottom right]. The contrasts further showed a dose-dependent effect in the magnitude and the duration of the impairment following SCOP as compared to SAL; all three doses of SCOP, $2 \mu \mathrm{g}, 5 \mu \mathrm{g}$, and $15 \mu \mathrm{g}$, significantly decreased choice accuracy in Post $1(p<0.001)$. These impairments were not present in Post 2 , following the lowest dose $(2 \mu \mathrm{g})$ but werc still present following two higher doses $(5 \mu \mathrm{g}$ and $15 \mu \mathrm{g})$. In Post 1 , SCOP, $2 \mu \mathrm{g}$ produced less of a decrease in choice accuracy than SCOP, 5 or $15 \mu \mathrm{g}(p<0.05, p<0.001$, respectively). In Post 2, SCOP, $2 \mu \mathrm{g}$ and $5 \mu \mathrm{g}$ produced a smaller decrease in choice accuracy than SCOP, $15 \mu \mathrm{g}(p<0.001, p<$ 0.05 , respectively). A similar pattern of results was obtained when performance in Post 1 and Post 2 was contrasted against baseline separately for each dose: all three doses of SCOP pro- 

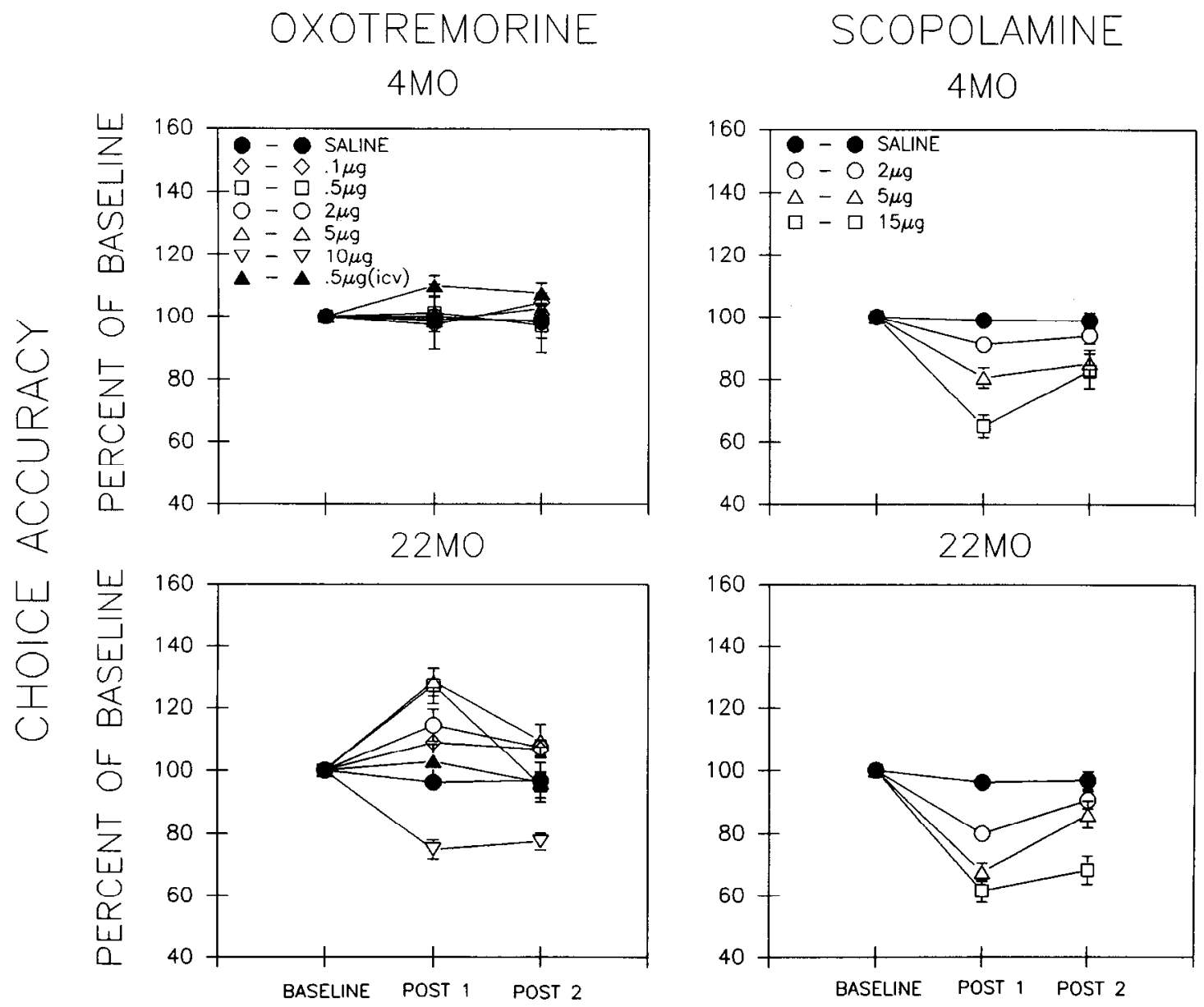

Figure 3. Choice accuracy in spatial alternation following infusions of OXO and SCOP in the $4 \mathrm{MO}$ and the $22 \mathrm{MO}$ rats. Choice accuracy is expressed as the percentage change from baseline during Post 1 and Post 2. The left panel presents the data following intraseptal OXO: top, 4MO rats; bottom, 22MO rats. The right panel presents the data following intraseptal SCOP: top, 4MO rats; bottom, 22MO rats. SAL (solid circles) and intraventricular OXO (solid triangles) had no effect on choice accuracy. Intraseptal OXO and SCOP (open symbols) produced a dose-, period-, and age-dependent change in choice accuracy.

duced a decrease in the choice accuracy in Post 1 ( $p$ values $<$ 0.001 ), and the two higher doses of SCOP, $5 \mu \mathrm{g}$ and $15 \mu \mathrm{g}$, produced a decrease in the choice accuracy in Post $2(p<0.05$ and $p<0.001$, respectively).

Although an overall ANOVA (dose $\times$ age $\times$ period) did not result in a significant dose $X$ age interaction, the results from the focused ANOVA described above suggested that the $22 \mathrm{MO}$ group was more sensitive to the SCOP treatment (all three doses, $2 \mu \mathrm{g}, 5 \mu \mathrm{g}$, and $15 \mu \mathrm{g}$, produced an impairment), than the $4 \mathrm{MO}$ group (only $5 \mu \mathrm{g}$ and $15 \mu \mathrm{g}$ produced an impairment).

\section{Hippocampal theta}

Reliable hippocampal theta was obtained from 22 of 26 rats that completed behavioral testing. The 22MO group had a lower peak theta frequency than the $4 \mathrm{MO}$ group $(p<0.01)$. The mean peak frequency for the $22 \mathrm{MO}$ group was $7.1 \pm 0.1 \mathrm{~Hz}$, and for the $4 \mathrm{MO}$ group was $7.6 \pm 0.1 \mathrm{~Hz}$. The two groups did not differ in peak power of theta $(p>0.1)$. Drug infusion significantly altered both theta parameters, dependent upon the drug, dose, age, and the time after infusion (Figs. 4, 5).

Saline vehicle. Saline, when compared to baseline, had no significant effect on peak power, or on peak frequency of the theta in either the $4 \mathrm{MO}$ or the $22 \mathrm{MO}$ rats, indicating that the infusion process itself did not alter theta (Figs. 4, 5).
Oxotremorine. OXO shifted the peak frequency of theta towards a lower frequency [dose effect; $F(5,67)=3.1, p<0.05$; dose $\times$ period, $F(10,134)=3.6, p<0.001$; Fig. 4, left $]$, and increased the power of theta [dose $\times$ period, $F(10,134)=1.9$, $p<0.05$; Fig. 5, left].

In the $4 \mathrm{MO}$ rats, peak frequency was significantly shifted towards the lower frequency as compared to SAL [Focused ANOVA, dose effect, $F(5,27)=2.8, p<0.05$; dose $\times$ period, $F(10,54)=3.6, p<0.001$; Fig. 4 , top left]. The magnitude of the shift increased with the dose; OXO, $0.1 \mu \mathrm{g}$ and $0.5 \mu \mathrm{g}$, had no effect, whereas OXO, $2 \mu \mathrm{g}$ and $5 \mu \mathrm{g}$, significantly shifted the peak frequency in Post 1 from $7.5 \pm 0.1$ to $6.4 \pm 0.3 \mathrm{~Hz}$, respectively ( $p<0.005$ ), and from $7.7 \pm 0.3$ to $6.9 \pm 0.3 \mathrm{~Hz}$ $(p<0.01)$, respectively. By Post 2 , peak frequency had returned to SAL levels following the smaller dose of OXO, $2 \mu \mathrm{g}$, whereas it was still significantly shifted to $6.8 \pm 0.3 \mathrm{~Hz}$ following $\mathrm{OXO}$, $5 \mu \mathrm{g}(p<0.05)$. A similar pattern of results was obtained for separate comparisons of Post 1 and Post 2 against baseline for each dose: $\mathrm{OXO}, 0.1 \mu \mathrm{g}$ and $0.5 \mu \mathrm{g}$, had no effect, while $\mathrm{OXO}$, $2 \mu \mathrm{g}$ and $5 \mu \mathrm{g}$, produced a significant shift in Post $1(p$ values $<0.05)$. This effect persisted in Post 2 only following OXO, 5 $\mu \mathrm{g}(p<0.05)$. OXO, $0.5 \mu \mathrm{g}$, infused into lateral ventricles did not affect peak frequency.

The peak power of theta was significantly increased [period 


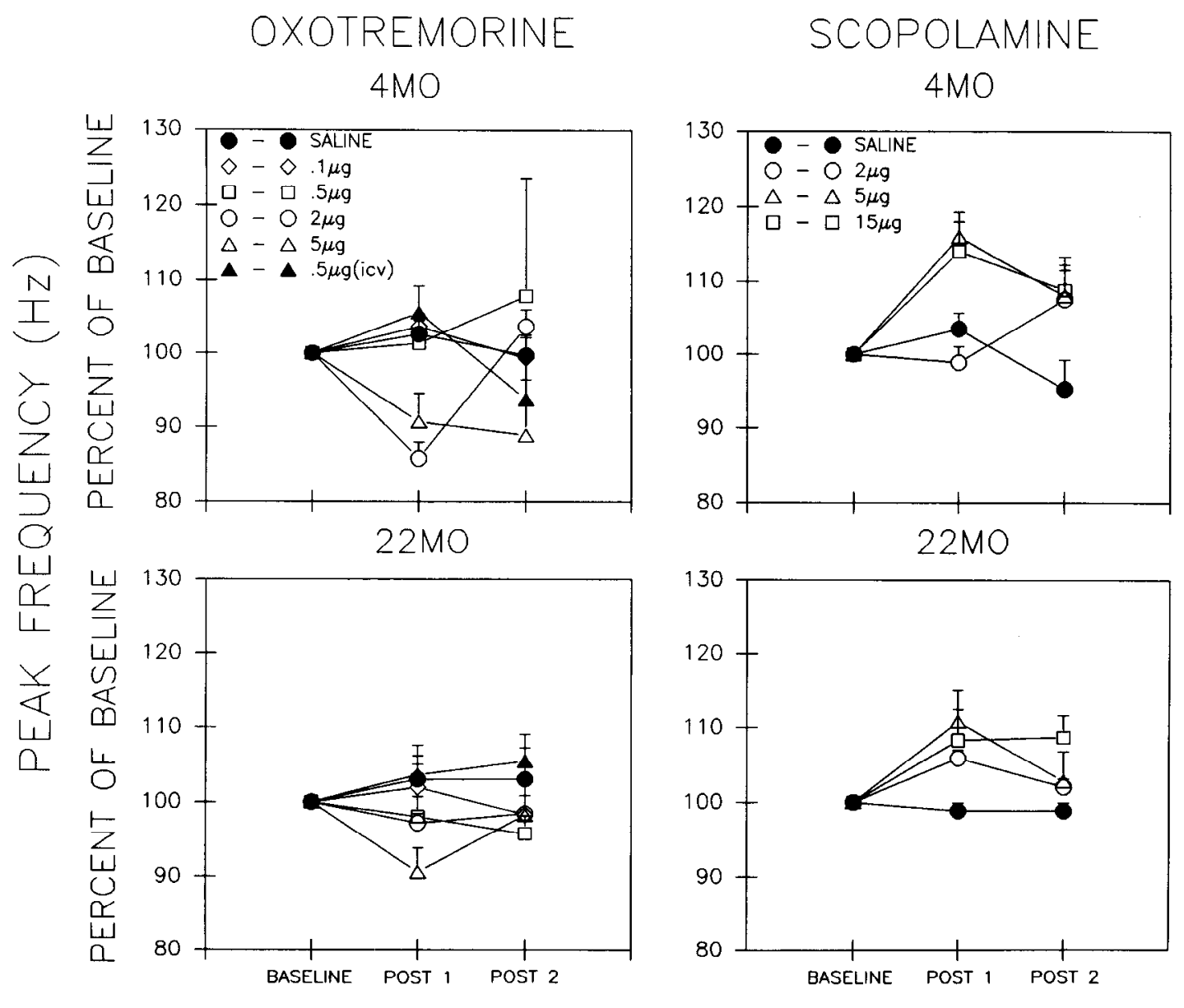

Figure 4. Frequency of hippocampal theta rhythm following infusion of OXO and SCOP in the $4 \mathrm{MO}$ and the $22 \mathrm{MO}$ rats. The peak theta frequency is expressed as the percentage change from baseline during Post 1 and Post 2. The left panel presents data following intraseptal OXO: top, 4MO rats; bottom, 22MO rats. The right panel presents data following intraseptal SCOP: top, 4MO rats; bottom, 22MO rats. Other symbols are the same as in Figure 3.

effect; $F(2,54)=5.4, p<0.01]$, dependent upon the dose of OXO [dose $\times$ period, $F(10,54)=2.1, p<0.05$; Fig. 5, left]. $\mathrm{OXO}, 5 \mu \mathrm{g}$, increased the power of theta in Post 1 from 0.022 \pm 0.01 to $0.035 \pm 0.01$. In Post 2 , the power of theta had returned to SAL levels. A similar pattern of results was obtained from separate comparisons of Post 1 and Post 2 against baseline separately for each dose: lower doses of OXO had no effect, whereas $\mathrm{OXO}, 5 \mu \mathrm{g}$, produced a significant increase of power in Post $1(p<0.05)$. The effect was not present in Post 2. OXO, $0.5 \mu \mathrm{g}$, infused into lateral ventricles did not affect peak power.

In the $22 \mathrm{MO}$ rats, peak frequency was shifted towards a lower frequency as compared to SAL (Fig. 4, bottom left). This effect approached significance [Focused ANOVA, dose $\times$ period, $F(10,80)=1.9, p<0.06]$. A significant effect of dose occurred in Post $1[F(5,40)=2.7, p<0.05]$, which was due mainly to the effect of OXO, $5 \mu \mathrm{g}$ which produced a shift of frequency from $7.2 \pm 0.2$ to $6.5 \pm 0.2 \mathrm{~Hz}$. In Post 2 , peak frequency had returned to SAL levels following all doses. Separate comparisons for each dose for Post 1 and Post 2 against haseline yield a similar pattern of results: $\mathrm{OXO}, 5 \mu \mathrm{g}$, produced a significant shift in Post 1 ( $p$ values $<0.05)$, which was not present in Post 2.

The peak power of theta in the $22 \mathrm{MO}$ rats was significantly increased [period effect; $F(2,80)=3.4, p<0.05$; Fig. 5 , bottom left]. OXO, $5 \mu \mathrm{g}$, increased the power of theta in Post 1 from
$0.043 \pm 0.01$ to $0.078 \pm 0.04$. This increase was significant as compared with SAL ( $p$ values $<0.05$ ). In Post 2 , the power of theta had returned to the SAL level. Separate comparisons across the three periods for each dose yielded the similar pattern of results. OXO, $0.5 \mu \mathrm{g}$, infused into lateral ventricles did not affect peak power.

Scopolamine. SCOP shifted the peak frequency of theta towards a higher frequency [dose effect; $F(3,44)=3.2, p<0.05$; dose $\times$ period, $F(6,88)=2.8, p<0.01$; Fig. 4 , right $]$, and reduced the peak power of theta Iperiod effect, $F(2,86)=10.2$, $p<0.001$; Fig. 5, right].

In the $4 \mathrm{MO}$ rats, the peak frequency of theta was significantly shifted towards a higher frequency as compared to SAL [Focused ANOVA, dose effect, $F(3,23)=3.9, p<0.05$; dose $\times$ period, $F(6,46)=3.6, p<0.005$; Fig. 4 , top right]. SCOP, 5 $\mu \mathrm{g}$, and $15 \mu \mathrm{g}$, produced a significant shift of theta toward a higher frequency in Post 1 from $7.8 \pm 0.2$ to $8.3 \pm 0.2 \mathrm{~Hz}$, and from $7.7 \pm 0.3$ to $8.8 \pm 0.3$, respectively ( $p$ values $<$ $0.05)$, and in Post 2 to $8.3 \pm 0.2$ and $8.3 \pm 0.3 \mathrm{~Hz}$, respectively ( $p$ values $<0.05$ ). SCOP, $2 \mu \mathrm{g}$, produced no shift of theta in Post $1(7.0 \pm 0.4)$ followed by the shift in Post 2 to $8.3 \pm 0.2$ $\mathrm{Hz}(p<0.05)$. Separate comparisons for each dose for Post 1 and Post 2 against baseline yield a similar pattern of results: SCOP, $2 \mu \mathrm{g}$, had no effect, while SCOP, $5 \mu \mathrm{g}$ and $15 \mu \mathrm{g}$, pro- 

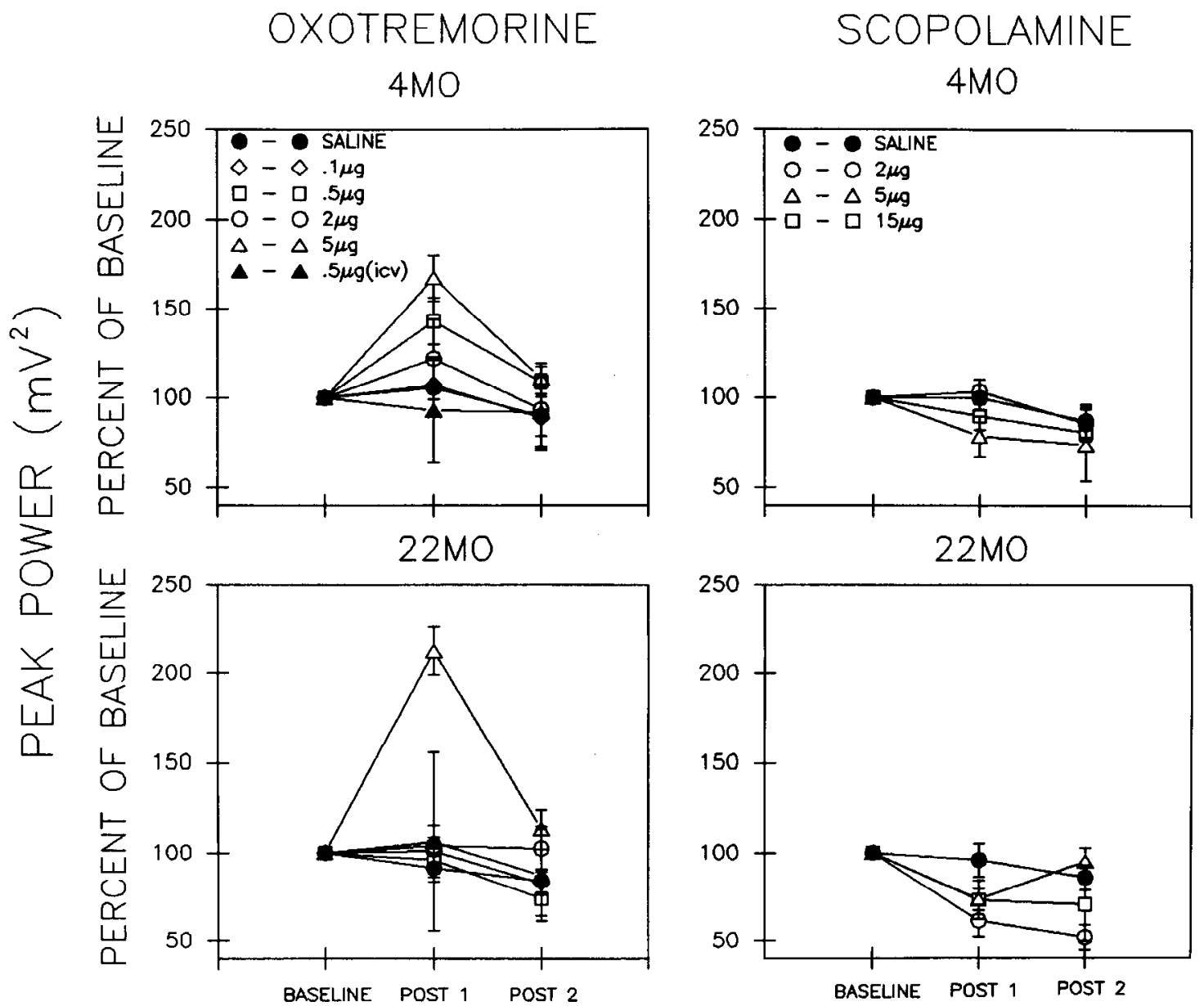

Figure 5. Spectral power of hippocampal theta rhythm following infusion of OXO and SCOP in $4 \mathrm{MO}$ and $22 \mathrm{MO}$ rats. Peak theta power is expressed as a percentage change of baseline during Post 1 and Post 2. The left panel presents data following intraseptal infusions of OXO: top, $4 \mathrm{MO}$ rats; bottom, 22MO rats. The right panel presents data following intraseptal SCOP: top, $4 \mathrm{MO}$ rats; bottom, 22MO rats. Other symbols are the same as in Figure 3.

duced a significant shift towards a higher frequency in Post 1 $(p$ values $<0.05)$ and in Post 2 ( $p$ values $<.0 .05$ ).

Overall, in the $4 \mathrm{MO}$ rats, the peak power of theta was significantly reduced [period effect; $F(2,46)=5.5, p<0.01$; Fig. 5 , top right], due to a decrease in power from baseline; 0.055 \pm 0.01 to Post $1 ; 0.047 \pm 0.01(p<0.05)$. When separate comparisons were performed for each dose, none of the doses of SCOP reached the significance level when compared to either $\mathrm{SAL}$ or to the baseline.

In the $22 \mathrm{MO}$ rats, peak frequency was shifted by SCOP towards a higher frequency as compared to SAL [Focused ANOVA, period effect, $F(2,42)=4.8, p<0.01$; Fig. 4 , bottom right]. Saline, when compared with all three doses of SCOP, indicated significant differences in Post $1(p<0.01)$ and in Post $2(p<$ 0.05 ). Two doses of SCOP, $2 \mu \mathrm{g}$ and $5 \mu \mathrm{g}$, produced a shift of frequency from $7.4 \pm 0.1$ to $7.8 \pm 0.1$ in Post 1 and to $7.5 \pm$ 0.2 in Post 2 , and from $7.2 \pm 0.2$ to $8.0 \pm 0.4$ in Post 1 and to $7.3 \pm 0.3$ in Post 2 , respectively. These effects reached the significance level when compared separately with SAL ( $p$ values $<0.05$ ). Separate comparisons for each dose for Post 1 and Post 2 against baseline yield a similar pattern of results; SCOP, $2 \mu \mathrm{g}$, $5 \mu \mathrm{g}$, and $15 \mu \mathrm{g}$, produced a significant shift towards a higher frequency in Post 1 ( $p$ values $<0.05$ ). In Post 2 , following SCOP, $15 \mu \mathrm{g}$, the frequency shift was still present $(p<0.05)$.
The peak power of theta was significantly reduced by SCOP in Post 1 and in Post 2 [period effect; $F(2,40)=5.2, p<0.01$; Fig. 5, bottom right]. This effect was significant mainly due to the decrease in peak power from baseline, $0.047 \pm 0.01$ to Post $1,0.031 \pm 0.01$, when all three doses of SCOP were included in the analyses $(p<0.01)$. However, when contrasts were performed separately for each dose, the effects approached significance $(0.06<p<0.08)$

\section{Evoked potential}

The dentate response to perforant path stimulation was obtained in 16 of the 26 rats that had completed behavioral testing, a number that yielded four to eight observations in each condition. These relatively small sample sizes may have contributed to the less robust effects observed in the evoked response measures. Measures of the baseline evoked responses were not different between the $4 \mathrm{MO}$ and the $22 \mathrm{MO}$ groups. However, there was a difference in the pEPSP slope, but not the population spike or the pEPSP amplitudes, between the $4 \mathrm{MO}$ and the 22MO groups for the maximal evoked response, but the difference was not maintained at the $50 \%$ maximal stimulus currents used for the baseline and drug conditions.

Saline vehicle. Saline, when compared to baseline, had no 


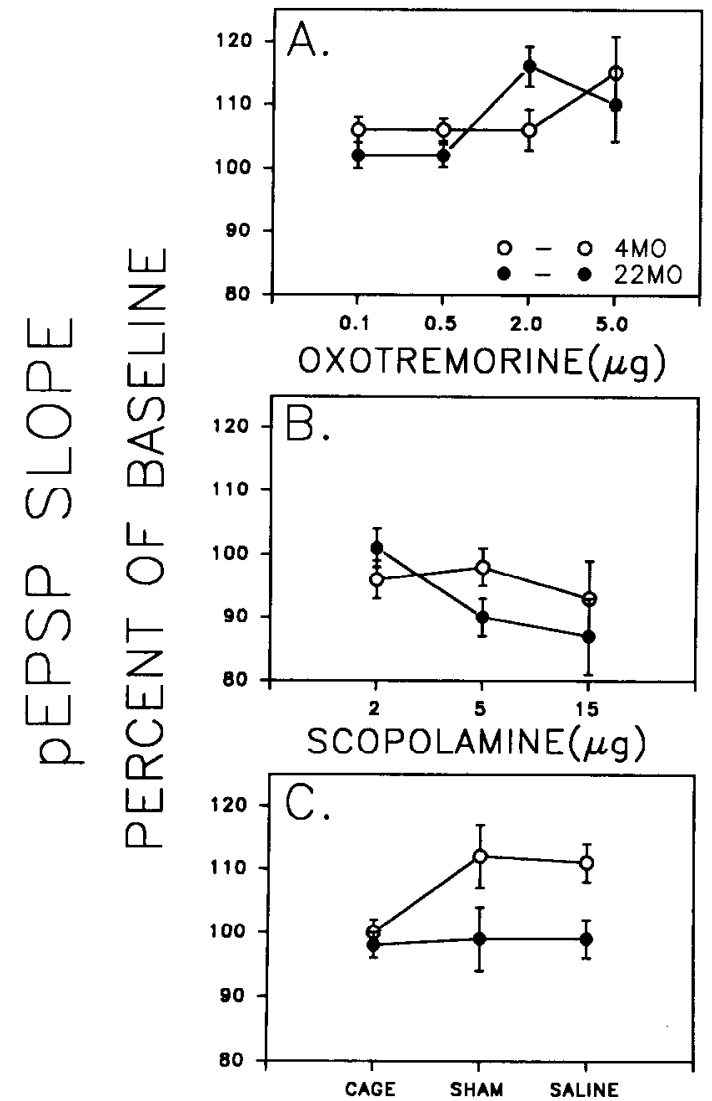

Figure 6. The slope of the pEPSP following intraseptal infusion of OXO and SCOP in the $4 \mathrm{MO}$ and the 2.MO rats. The PFPSP slope is expressed as the percentage change from baseline to Post 1. OXO $(A)$ increases and SCOP $(B)$ decreases the slope of the pEPSP in the 22MO and the $4 \mathrm{MO}$ groups, respectively. $C$, The effect of saline, sham infusion, and sham infusion without behavioral testing $(C A G E)$. Saline and sham infusion increased the slope in the $4 \mathrm{MO}$ but not the $22 \mathrm{MO}$ rats (see Discussion).

significant effect on measures of the evoked response in either the $4 \mathrm{MO}$ or the $22 \mathrm{MO}$ groups.

Oxotremorine. Although the overall effect of $\mathrm{OXO}$ was not significant, there was a marginally significant age $\times$ dose interaction $(p=0.09$ ). In the $4 \mathrm{MO}$ group, OXO had no effect (Fig. 6A).

In the $22 \mathrm{MO}$ group, a focused ANOVA revealed an increase in the slope of the pEPSP (dose effect, $p<0.05$ ). The contrasts showed this difference to be between the vehicle (SAL intraseptal and SAL, i.c.v.) and active doses $(0.5 \mu \mathrm{g}, 2 \mu \mathrm{g}$, and $5 \mu \mathrm{g})$ of OXO.

Scopolamine. There was a significant overall effect of SCOP $[F(3,28)=3.04, p<0.05]$, but not an effect of age, nor a dose $\times$ age interaction. In the $4 \mathrm{MO}$ group, SCOP had no significant effect on the pEPSP slope (Fig. $6 B$ ).

In the 22MO group, SCOP produced a decrease in the pEPSP slope. Contrasts further showed the effect between the vehicle and the $15 \mu \mathrm{g}$ dose in Post $1(p<0.05)$ and this effect recovered to SAL levels by Post 2 .

\section{Discussion}

The present experiment demonstrates that in aged rats, selective activation of the MSA neurons with oxotremorine, a cholinergic agonist, reduces the magnitude of age-related cognitive impair- ments in working memory as assessed by spatial alternation in the $\mathrm{T}$-maze. In the $22 \mathrm{MO}$ rats with impaired working memory, intraseptal OXO enhanced choice accuracy, while a control infusion of SAL had no effect on performance. The smallest effective dose of OXO was $0.5 \mu \mathrm{g}$ and this dose improved choice accuracy transiently (Post 1 only), when given to MSA but not the cerebral ventricles. The highest effective dose was 10-fold higher, $5 \mu \mathrm{g}$, and this dose improved accuracy during both periods of testing (Post 1 and Post 2). The smallest dose of OXO, $0.1 \mu \mathrm{g}$, did not effect choice accuracy.

In the 22MO group, higher doses of OXO had a substantial impact on hippocampal physiology. OXO, $5 \mu \mathrm{g}$, lowered peak theta frequency and increased the peak power of hippocampal theta. These results are consistent with the findings that another muscarinic agonist, carbachol, produces a decrease in theta frequency (Lawson and Bland, 1993) and an increase in the power of theta (Monmaur and Breton, 1991). In 22MO rats, OXO also substantially increased the pEPSP slope. Given the presence of cholinergic receptors on both cholinergic and GABAergic neurons of MSA (Leranth and Frotscher, 1989), the effect of intraseptal infusions of a cholinergic agonist probably increases the activity of both types of neurons (Smythe et al., 1992): the cholinergic neurons predominantly exert excitatory action on the hippocampal pyramidal cells (Bland, 1986; Nicoll, 1985); the GABAergic neurons project to the hippocampal interneurons, and through a disinhibitory mechanism (inhibition of inhibition) activates the hippocampal pyramidal cells (Freund and Antal, 1988). The relative depolarization state of principal hippocampal ncurons including dentate granulc cclls may account for the increase in pEPSP slope following OXO in $22 \mathrm{MO}$ rats.

The effects of OXO on behavior and electrophysiology indicate that MSA neurons of aged rats are still responsive to cholinergic agonists. In light of the cholinergic hypothesis of learning and memory (Bartus et al., 1985; Perry, 1986) and the degenerations in the cholinergic system as a result of aging (Olton and Markowska, 1992), these results support a mechanism by which a direct enhancement of the basal forebrain cholinergic system may lead to memory improvement in old age. However, given the possibility of disinhibition in the hippocampus as a result of modulation of the MSA, one cannot rule out the possibility that perhaps the effects on memory are actually a result of cholinergic influence on the GABAergic septohippocampal axis.

In the $4 \mathrm{MO}$ rats, none of the doses of OXO affected choice accuracy. However, selected doses of OXO, $2 \mu \mathrm{g}$ but not 0.5 $\mu \mathrm{g}$, have been found to influence the release of $\mathrm{ACh}$ in the hippocampus of young rats, when measured using microdialyses (Gorman et al., 1994). In the present study, OXO shifted hippocampal theta toward a lower frequency and increased the peak power of theta of the $4 \mathrm{MO}$ rats, similar to the $22 \mathrm{MO}$ rats. However, in contrast to the $22 \mathrm{MO}$ rats, OXO had no effect on pEPSP slope of the $4 \mathrm{MO}$ rats. This pattern of results suggests that performance during normal conditions in young rats cannot be used to predict responses to a neural manipulation under compromised conditions, and that changes in pEPSP slope but not in hippocampal theta may be a reliable indicator of mnemonic performance.

The improvement in working memory in aged rats was not obtained in young rats despite their less-then-perfect choice accuracy due to longer delay intervals used in behavioral training. The lack of behavioral improvement in young rats suggests that the septohippocampal system was functioning optimally before 
the infusion of OXO. Aged rats may be sensitive to these manipulations only because their brains are compromised by the aging process (deToledo-Morell et al., 1984, 1988; Biegon et al., 1986; Altavista et al., 1988, 1990; Fischer et al., 1989, 1991a,b). Consequently, cholinergic interventions with $\mathrm{OXO}$ may improve choice accuracy in aged rats because the cholinergic system is functioning at a suboptimal level. The young rats were matched in accuracy with the old rats so that there was an equal opportunity for improvement in the two groups. However, behavioral improvement was not observed in the 4MO group suggesting that the physiological basis for the decrease in accuracy with the longer delays in the young rats was different than for the agerelated impairment in the old rats.

The correlation between individual delay intervals and amount of improvement in choice accuracy was positive in the old group and negative in the young group indicating that with the longer delays there was a greater improvement in memory in the old rats but there was less improvement in the young rats. Neither of these correlations reached significance which further underscore above conclusion that different delay intervals account for the age-related differences in the response to the treatment.

The neural basis for the age-related impairment in working memory is likely to involve cholinergic mechanisms. The results from a parallel experiment demonstrate that the cholinergic agonist carbachol can alleviate mnemonic impairments produced by systemic injections of scopolamine in young rats (Givens and Olton, 1995). Thus, in two different amnesic syndromes produced either by scopolamine, in young normal rats, or age-related, in aged rats, two different cholinergic agonists (carbachol, oxotremorine) infused into the MSA alleviated the mnemonic impairment, suggesting that age-related impairments and scopolamine-induced impairments may operate through similar mechanisms.

The increase of the pEPSP slope in the 22MO, but not in the $4 \mathrm{MO}$ rats, following intraseptal infusions of $\mathrm{OXO}$ indicates an increased response of aged dentate granule cells to cortical excitatory input. There was a significant age-related difference in the baseline slope of the pEPSP, as has been previously noted (Barnes, 1979, 1994). The increase observed after intraseptal infusions of OXO brought the slope of the $22 \mathrm{MO}$ rats up to the normally seen level in the $4 \mathrm{MO}$ rats. The performance of the $4 \mathrm{MO}$ rats was matched with that of the $22 \mathrm{MO}$, but the performance level itself did not correlate with the baseline pEPSP measurements. A study into the effects of intraseptal OXO treatment in aging rats on long-term potentiation (LTP) found a decrease in the pEPSP slope as compared to an increase induced by saline $15 \mathrm{~min}$ after its infusion (Pang et al., 1993). The difference in this finding from the present results may be due to the presence of behavioral testing that preceded physiological recording in the latter.

One of the reasons for the lack of a significant effect of $\mathrm{OXO}$ on the pEPSP slope in the young rats may be the fact that saline itself caused a pEPSP slope increase. This effect was not seen in the group of old rats and it prompted us to do some additional experiments. Saline infusions were compared to sham infusions. It was found that sham infusions caused the slope to increase (Fig. 6C), leaving only the intervening behavior as the potential cause of the increase. Thus, another control group was run that had a sham infusion but was returned to the home cage instead of receiving behavioral testing before the physiological recording. In this group, there was no difference between baseline and
Post 1 . These data from the young rats are consistent with reports that the dentate evoked response can be enhanced by recent behavioral experience (Green et al., 1993), and/or by brain temperature increases that accompany behavioral testing (Moser et al., 1993a,b). These explanations may not apply to the 22MO group which did not have slope changes due to behavioral testing but was sensitive to intraseptal OXO. Careful investigation into brain temperature regulation in aging has not been done, but there is some indications that temperature control may be affected by aging process and contributes to the spatial memory deficits in the Morris water maze (Lindner and Gribkoff, 1991). It is also possible that the lack of a spontaneous pEPSP slope shift in the old group, may be related to a decreased locomotor activity during the maze task as a consequence of their shorter delays intervals (Erickson et al., 1991).

Scopolamine had a profound effect on choice accuracy and hippocampal physiology. SCOP reduced choice accuracy, shifted hippocampal theta peak towards a higher frequency, and decreased the peak power in dose-dependent fashion: the highest dose of SCOP, $15 \mu \mathrm{g}$, produced the greatest impairment. These results are consistent with other findings suggesting that if MSA function is disrupted by intraseptal anticholinergic drugs, then theta activity in the hippocampus is also disrupted (Stewart and Fox, 1990; Lawson and Bland, 1993).

Aging increased sensitivity to SCOP: in the $22 \mathrm{MO}$ rats, the lowest dose of SCOP, $2 \mu \mathrm{g}$, produced a working memory impairment whereas in the $4 \mathrm{MO}$ rats it had no effect. In both the $4 \mathrm{MO}$ and the $22 \mathrm{MO}$ rats, SCOP, $15 \mu \mathrm{g}$, decreased choice accuracy to chance level (about 50\%), but the duration of the decrease was longer in the $22 \mathrm{MO}$ group, in which choice accuracy was still at the chance level $90 \mathrm{~min}$ after infusion. In the $4 \mathrm{MO}$ group choice accuracy had partially recovered by this time. This result is compatible with findings reporting age-related compromises of the septohippocampal system (Fischer et al., 1989). The impairment produced by intraseptal infusions of SCOP in the impaired rats indicates that the MSA continues to contribute to mnemonic processing in spite of the age-related deterioration. These results are consistent with other findings indicating that lesions of the basal forebrain cholinergic system lower the threshold for impairment in memory induced by cholinergic blockade (Gage and Bjorklund, 1986; Nilsson et al., 1987; Markowska and Wenk, 1991).

Aging also increased the sensitivity of physiological measures to scopolamine. In aged rats, SCOP, $2 \mu \mathrm{g}$, shifted theta towards a higher frequency during the entire testing period, whereas in young rats the effect was transient. The shift of theta frequency following SCOP, $15 \mu \mathrm{g}$, was present during the entire testing period (Post 1 and Post 2) in both age groups. SCOP at all doses slightly decreased the peak power of theta. In the $22 \mathrm{MO}$, these effects tended to be greater than in $4 \mathrm{MO}$ rats, although they were not significant in either group.

In the present study, OXO and SCOP produced a substantial effect on peak theta frequency. OXO shifted hippocampal theta peak towards a lower frequency, whereas SCOP shifted hippocampal peak theta towards a higher frequency. In normal conditions, the theta rhythm may represent two separate theta generators in the hippocampus: (1) a lower frequency $(4-7 \mathrm{~Hz})$ cholinergic theta and (2) a higher frequency $(6-9 \mathrm{~Hz})$ atropineinsensitive theta (Bland, 1986). In the present study, the shift of the peak frequency toward a higher frequency produced by SCOP may represent a loss of the lower frequency component of theta. Conversely, the shift in peak frequency towards a lower 
frequency produced by $\mathrm{OXO}$ may represent an enhancement of the cholinergic component of the theta.

Aging itself had a substantial impact on the peak power of theta and was associated with a shift of the theta peak towards a lower frequency. The lower theta frequency is most likely due to a decrease in the rhythmic burst frequency of septohippocampal neurons in aged rats (Lamour et al., 1984, 1989). The hippocampus may operate optimally at a particular frequency, and a higher or a lower frequency may disrupt its function. Treatments that restore the normal theta frequency may optimize its ability to process new information. Therefore, the predicted effect of OXO would be to shift toward a higher frequency to restore the normal theta frequency. However, this was not the case. OXO shifted the theta peak towards a lower frequency, the same direction as the aging process. Alternatively, this data may suggest that the hippocampus may operate optimally at a wider range of theta frequency dependent upon age.

The slowing of the theta frequency with aging may be unrelated to an age-related decline in working memory whereas drug-induced changes in theta frequency may directly impact working memory. The age-related slowing of theta frequency may be similar to the general age-dependent slowing of reaction time performance that is unrelated to cognitive function (Burwell and Gallagher, 1993). Conversely, drug-induced changes in theta frequency lead to improvements in working memory (Ammassari-Tuele et al., 1991; Givens and Olton, 1994). These druginduced effects may be mediated by Type 2 theta. The cholinergic agonist carbachol does not affect the frequency of movement-related theta, but elicits a significantly lower frequency of theta during immobility (Lawson et al., 1993). The lowering of the theta frequency in old rats by OXO may correspond to a relative shift from movement-related theta to Type 2 , or "sensory processing" theta, and despite an overall lower baseline frequency in the old rats, is associated with an improvement in cognitive performance.

Although, the present results are consistent with the view that cholinergic dysfunction may, in part, underlie the cognitive deficits associated with aging. It has become increasingly evident that cholinergic dysfunction cannot provide a complete account for these deficits. For example, nucleus basalis magnocellularis (NBM) lesions produced by the neurotoxin quisqualic acid reduce cholinergic input to the cortex more completely than NBM lesions produced by ibotenic acid, yet quisqualic acid lesions produce only a minimal memory deficit (Dunnett et al., 1987; Wenk et al., 1989; Markowska et al., 1990). Age-related alterations in cholinergic function might well interact with those in other neurotransmitter systems (Markowska et al., 1989) to produce additive or even synergistic effects on cognition (Decker and McGaugh, 1990; Gallagher et al., 1990).

Taken together, the current results (1) represent a successful attempt to improve spatial memory in old rats, (2) suggest that discrete stimulation of the septohippocampal system may serve as a mechanism for significant cognitive improvement in agerelated memory deficits, and (3) indicate that targeted cholinergic activation of the basal forebrain may be a fruitful direction for the development of the treatment of memory deficits in aging.

\section{References}

Aggleton JP, Blindt HS, Candy JM (1989) Working memory in aged rats. Behav Neurosci 103:975-983.

Altavista MC, Bentivoglio AR, Crociani P, Rossi P, Albanses A
(1988) Age-dependent loss of cholinergic neurons in the basal ganglia of rats. Brain Res 455:177-181.

Altavista MC, Rossi P, Bentivoglio AR, Crociani P, Albanses A (1990) Aging is associated with a diffuse impairment of forebrain cholinergic neurons. Brain Res 508:51-59.

Ammassari-Teule M, Maho C, Sara SJ (1991) Clonidine reverses spatial learning deficits and reinstates $\theta$ frequencies in rats with partial fornix section. Behav Brain Res 45:1-8.

Barnes CA (1979) Memory deficits associated with senescence: a neurophysiological and behavioral study in the rat. J Comp Physiol Psychol 93:74-104.

Barnes CA (1994) Normal aging: regionally specific changes in hippocampal synaptic transmission. Trends Neurosci 17:13-18.

Barnes CA, McNaughton BL (1985) An age comparison of the rates of acquisition and forgetting spatial information in relation to longterm enhancement of hippocampal synapses. Behav Neurosci 99: $1040-1048$.

Bartus RT, Dean RL (1985) Developing and utilizing animal models in the search for an effective treatment for age-related memory disturbances. In: Normal aging, Alzheimer's disease and senile dementia (Gottfired CG, ed), pp 231-267. Brussels: University of Brussels.

Bartus RT, Reginald LD, Pontecorvo MJ, Flicker C (1985) The cholinergic hypothesis: a historical overview, current perspective, and future directions. In: Memory dysfunctions: an integration of animal and human research from preclinical and clinical perspectives (Olton DS, Gamzu E, Corkin S, eds), pp 332-358. New York: New York Academy of Sciences.

Beatty WW, Bierly RA (1985) Scopolamine degrades spatial working memory but spares spatial reference memory: dissimilarity of anticholinergic effects and restriction of distal visual cues. Pharmacol Biochem Behav 23:1-6.

Biegon A, Greenberger V, Segal M (1986) Quantitative histochemistry of brain acetylcholinesterase and learning in the aged rat. Neurobiol Aging 7:215-217

Bland BH (1986) The physiology and pharmacology of hippocampal formation theta rhythms. Prog Neurobiol 2.6:1-54

Brioni JD, Decker MW, Gamboa LP, Izquierdo I, McGaugh JL (1990) Musimol injections in the medial septum impair spatial learning. Brain Res 522:227-234.

Burwell RD, Gallagher M (1993) A longitudinal study of reaction time performance in Long-Evans rats. Neurobiol Aging 14:57-64.

Chrobak JJ, Stackman RW, Walsh TJ (1989) Intraseptal administration of muscimol produces dose-dependent memory impairments in the rat. Behav Neural Biol 52:357-369.

Decker MW, Gallagher (1987) Scopolamine-disruption of radial arm maze performance: modification by noradrenergic depletion. Brain Res 417:59-69.

Decker MW, McGaugh JL (1990) The role of interactions between the cholinergic system and other neuromodulatory systems in learning and memory. Synapse 7:151-168.

Decker MW, Radek RJ, Majchrzak MJ, Anderson DJ (1992) Differential effects of medial septal lesions on spatial-memory tasks. Psychobiology 20:9-17.

deToledo-Morrell L, Morrell F, Fleming S (1984) Age- dependent deficits in spatial memory are related to impaired hippocampal kindling. Behav Neurosci 98:902-907.

deToledo-Morrell L, Geinisman Y, Morrell F (1988) Individual differences in hippocampal synaptic plasticity as a function of aging: behavioral, electrophysiological and morphological evidence. In: Neural plasticity: a lifespan approach, pp 283-328. New York: Liss.

Dunnett SB, Whishaw IQ, Jones GH, Bunch ST (1987) Behavioral, biochemical and histochemical effects of different neurotoxic amino acids injected into nucleus basalis magnocellularis of rats. Neuroscience 20:653-669.

Erickson CA, Barnes CA, McNaughton BL, Gibbos DF (1991) An age comparison of short-term exploratory modulation of rat perforant path synaptic efficacy. Soc Neurosci Abstr 17:1394.

Fischer W, Wictorin K, Bjorklund K, Williams LR, Varon S, Gage FH (1987) Amelioration of cholinergic neuron atrophy and spatial memory impairment in aged rats by nerve growth factor. Nature 329:65-68

Fischer W, Gage FH, Bjorklund A (1988) Degenerative changes in 
forebrain cholinergic nuclei correlate with cognitive impairments in aged rats. Eur Neurosci Assoc 1:34-45.

Fischer W, Gage FH, Bjorklund A (1989) Degenerative changes in forebrain cholinergic nuclei correlate with cognitive impairments in aged rats. Eur J Neurosci 1:34-45.

Fischer W, Bjorklund A, Chen K, Gage FH (1991a) NGF improves spatial memory in aged rodents as a function of age. $J$ Neurosci 11: 1889-1906.

Fischer W, Chen KS, Gage FH, Bjorklund A (1991b) Progressive decline in spatial learning and integrity of forebrain cholinergic neurons in rats during aging. Neurobiol Aging 13:9-23.

Freund TF, Antal M (1988) GABA-containing neurons in the septum control inhibitory interneurons in the hippocampus. Nature 336: 170-173.

Frotscher M, Leranth C (1985) Cholinergic innervation of the rat hippocampus as revealed by choline acetyltransferase immunocytochemistry: a combined light and electron microscopic study. J Comp Neurol 239:237-246.

Gage FH, Bjorklund A (1986) Cholinergic septal grafts into the hippocampal formation improve spatial learning and memory in aged rats by an atropine sensitive mechanism. J Neurosci 6:2837-2847.

Gage FH, Kelly PAT, Bjorklund A (1984) Regional changes in brain glucose metabolism reflect cognitive impairments in aged rats. $J$ Neurosci 4:2856-2865.

Gallagher M, Burwell RD, Kodal MH, McKinney M, Southerland S, Vella-Roundtree L, Lewis MH (1990) Markers for biogenic amines in the aged rat brain: relationship to decline in spatial learning ability. Neurobiol Aging 11:507-515.

Geinisman Y, deToledo-Morrell L, Morrell F (1986) Aged rats need a preserved complement of perforated axospinous synapses per hippocampal neuron to maintain good spatial memory. Brain Res 398: 266-275.

Gilad G, Rabey JM, Tizabi Y, Gilad VH (1987) Age-dependent loss and compensatory changes of septohippocampal cholinergic neurons in two rat strains differing in longevity and response to stress. Brain Res 436:311-322.

Givens BS, Olton DS (1990) Cholinergic and GABAergic modulation of medial septal area: effect on working memory. Behav Ncurosci 104:849-855.

Givens BS, Olton DS (1994) Bidirectional modulation of scopolamine induced working memory impairments by muscarinic activation of the medial septal area. Neurol Biol Learn Mem, in press.

Gomez-Pinilla F, Cotman CW, Nieto-Sampedro M (1989) NGF-receptor immunoreactivity in aged rat brain. Brain Res 479:255-262.

Gorman LK, Pang K, Frick KM, Givens B, Olton DS (1994) Acetylcholine release in the hippocampus: effects of cholinergic and GABAergic compounds in the medial septal area. Neurosci Lett 166:199-202.

Green EJ, Barnes CA, McNaughton BL (1993) Behavioral state dependence of homo- and hetero-synaptic modulation of dentate gyrus excitability. Exp Brain Res 93:55-65.

Hagan JJ, Tweedic F, Morris RGM (1986) Lack of task specificity and absence of posttraining effects of atropine on learning. Behav Neurosci 100:483-493.

Hagan JJ, Salamone JD, Simpson J Iversen SD, Morris RGM (1988) Place navigation in rats is impaired by lesions of medial septum and diagonal band but not nucleus basalis magnocellularis. Behav Brain Res 27:9-21.

Ingram DK, London ED, Goodrick CL (1981) Age and neurochemical correlates of radial maze performance in rats. Neurobiol Aging 2:41-47.

Lamour Y, Dutar P, Jobert A (1984) Septohippocampal and other medial septal-diagonal band neurons: electrophysiological and pharmacological properties. Brain Res 309:227-239.

Lamour Y, Bassant MH, Jobert A, Joly M (1989) Septo-hippocampal ncurons in the aged rat: relation between their electrophysiological and pharmacological properties and behavioral performances. Neurobiol Aging 10:181-186.

Landfield PW (1988) Hippocampal neurobiological mechanisms of age-related memory dysfunction. Neurobiol Aging 9:571-579.

Lawson VH, Bland BH (1993) The role of the septohippocampal pathway in the regulation of hippocampal field activity and behavior: analysis by the intraseptal microinfusion of carbachol, atropine, and procaine. Exp Neurol 120:132-144.
Lebrun C, Durkin TP, Marighetto A, Jaffard R (1990) A comparison of the working memory performance of young and age mice combined with parallel measures of testing and drug-induced activations of septo-hippocampal and NBM-cortical cholinergic neurones. Neurobiol Aging 11:515-521.

Leranth C, Frotscher M (1989) Organization of the septal region in the rat brain: cholinergic-GABAergic interconnections and the termination of hippocampo-septal fibers. J Comp Neurol 289:304-314.

Lindner MD, Gribkoff VK (1991) Relationship between performance in the Morris water task, visual acuity, and thermoregulatory function in aged F-344 rats. Behav Brain Res 45:45-55.

Markowska AL, Wenk GL (1991) Serotonin influences the behavioral recovery of rats following nucleus basalis lesions. Pharmacol Biochem Behav 38:731-737.

Markowska AL, Stone WS, Ingram DK, et al. (1989) Individual differences in aging: behavioral and neurobiological correlates. Neurobiol Aging 10:31-43.

Markowska AL, Wenk GL, Olton DS (1990) Nucleus basalis magnocellularis and memory: differential effects of two neurotoxin. Behav Neural Biol 54:13-26.

Markowska AL, Koliatsos VE, Breckler SJ, Price DL, Olton DS (1994) Human nerve growth factor improves spatial memory in aged but not in young rats. $J$ Neurosci 14:4815-4824.

Mizumori SJY, Perez GM, Alvarado MC, Barnes CA, McNaghton BL (1990) Reversible inactivation of the medial septum differentially affects two forms of learning in rats. Brain Res 528:12-20.

Monmaur P, Breton P (1991) Elicitation of hippocampal theta by intraseptal carbachol injection in freely moving rats. Brain Res 544: $150-155$

Moser E, Mathiesen I, Andersen P (1993a) Association between brain temperature and dentate field potentials in exploring and swimming rats. Science 259:1324-1326.

Moser E, Moser MB, Anderson P (1993b) Synaptic potentiation in the rat dentate gyrus during exploratory learning. Neuroreport $5: 317-320$

Nicoll RA (1985) The septo-hippocampal projection: a model cholinergic pathway. Trends Neurosci 8:533-536.

Nilsson OG, Shapiro ML, Gage FII, Olton DS, Bjorklund A (1987) Spatial learning and memory following fimbria-fornix transection and grafting of fetal septal neurons to the hippocampus. Exp Brain Res 67:195-215.

Numan R, Quaranta JR (1990) effects of medial septal lesions on operant delayed alternation in rats. Brain Res 531:232-241.

Olton DS, Markowska AL (1992) The aging septo-hippocampal system: its role in age-related memory impairments. In: Neuropsychology of memory (Squire LR, Butters N, eds). New York: Guilford.

Olton DS, Wenk GL (1987) Dementia: animal models of the cognitive impairments produced by degeneration of the basal forebrain cholinergic system. In: Psychopharmacology: the third generation of progress (Meltzer HY, ed), pp 941-953. New York: Raven.

Olton DS, Markowska AL, Voytko ML, Givens B, Wenk G (1990) Basal forebrain cholinergic system: a functional analysis. In: The basal forebrain: anatomy to function (Napier TC, Kalivas PW, Hanin I, eds). New York: Plenum.

Olton DS, Givens BS, Markowska AL, Shapiro M, Golski S (1992) Mnemonic functions of the cholinergic septohippocampal system In: Memory: organization and locus of change (Squire LR, Weinberger NM, McGaugh JL, eds). London: Oxford UP.

Pang K, Williams MJ, Olton DS (1993) Activation of the medial septal area attenuates LTP of the lateral perforant path and enhances heterosynaptic LTD of the medial perforant path in aged rats. Brain Res 632:150-160.

Perry EK (1986) The cholinergic hypothesis-ten years on. Brain Med Bull 42:63-69.

Smythe JW, Colom LV, Bland BH (1992) The extrinsic modulation of hippocampal theta dependents on the coactivation of cholinergic and GABAergic medial septal inputs. Neurosci Biobehav Rev 16: 289-308.

Stewart M, Fox SE (1990) Do septal neurons pace the hippocampal theta rhythm? Trends Neurosci 13:163-168.

Wenk G, Markowska AL, Olton DS (1989) Basal forebrain lesions and memory; alteration in neurotensin, not acetylcholine, may cause amnesia. Behav Neurosci 103:1624-1628. 